Article

\title{
Surface Profiling and Core Evaluation of Aluminum Honeycomb Sandwich Aircraft Panels Using Multi- Frequency Eddy Current Testing
}

\author{
${ }^{*}$ Tyler Reyno ${ }^{1}$, P. Ross Underhill2 ${ }^{2}$, Thomas W. Krause ${ }^{2}$, Catharine Marsden ${ }^{3}$, Diane Wowk ${ }^{1}$ \\ 1 Department of Mechanical and Aerospace Engineering, Royal Military College of Canada, Kingston, ON \\ 2 Department of Physics, Royal Military College of Canada, Kingston, ON \\ 3 Faculty of Engineering and Computer Science, Concordia University, Montréal, QC Canada \\ * tyler.reyno@rmc.ca; Tel.: +1 (613) 541-6000 ext. 6208
}

\begin{abstract}
Surface damage on honeycomb aircraft panels is often measured manually, and is therefore subject to variation based on inspection personnel. Eddy current testing (ECT) is sensitive to variations in probe-to-specimen spacing, or lift-off, and is thus promising for high resolution profiling of surface damage on aluminum panels. Lower frequency testing also allows inspection through the face sheet, an advantage over optical 3D scanning methods. This paper presents results from the ECT inspection of surface damage on an approximately flat aluminum honeycomb aircraft panel, and compares the measurements to those taken using optical 3D scanning technology. An ECT C-Scan of the dented panel surface was obtained by attaching the probe to a robotic scanning apparatus. Data was taken simultaneously at four frequencies of 25, 100, 400 and 1,600 kHz. A reference surface was then defined that approximated the original, undamaged panel surface, which also compensated for the effects of specimen tilt and thermal drift within the ECT instrument. Data was converted to lift-off using height calibration curves developed for each probe frequency. A damage region of 22,550 $\mathrm{mm}^{2}$ area with dents ranging in depth from $0.13-1.01 \mathrm{~mm}$ was analyzed. The method was accurate at $1,600 \mathrm{kHz}$ to within $0.05 \mathrm{~mm}(2 \sigma)$ when compared with 231 measurements taken via optical 3D scanning. Testing at $25 \mathrm{kHz}$ revealed a $3.2 \mathrm{~mm}$ cell size within the honeycomb core, which was confirmed via destructive evaluation. As a result, ECT demonstrates potential for implementation as a method for rapid in-field aircraft panel surface damage assessment.
\end{abstract}

Keywords: eddy current; multi-frequency eddy current; surface profiling; surface damage; honeycomb paneling

\section{Introduction}

Impact damage in all-aluminum honeycomb sandwich structures, such as wing surfaces and internal floor boards, may produce permanent denting of the aluminum skin accompanied by a buckled honeycomb core that often remains bonded to the skin [1]. Both the dent and core damage produced by an impact affect the residual strength of a panel and therefore, may compromise the structural integrity of the component, potentially leading to its failure [2]. Characterization of dent depth and area of dent in aircraft support structures is a key element used in the determination of remaining panel lifetime. Methods of evaluating damage in aluminum honeycomb sandwich structures have included X-ray and optical shearography [3]. Portable methods for the assessment of honeycomb panel denting damage have involved dial or digital depth gauge [4-11], a ruler, or, in some cases, a high resolution electronic indicator $[12,13]$. However, a disadvantage of these methods is that measurements are subject to interpretation and variation based on inspection personnel. Manual measurements may also require repetition to confirm observations. Creaform Inc. is developing and marketing a portable optical 3D scanning system for the assessment of hail damage on in-service aircraft. However, this technique does not offer the added benefit of inspecting core 
geometries in these panels. For the panel considered in this study, dents corresponding with barely visible impact damage (BVID) were of interested, which are typically the result of low-velocity impact.

Eddy current testing (ECT) is commonly used for the detection of surface breaking flaws in conductive materials [14]. Applications of ECT for flaw detection include piping and heat exchanger inspection of nuclear power plants [15-17]. For these applications, it offers advantages such as high sensitivity, rapid scanning, and flexibility [14]. ECT is also used to evaluate defects in various other environments and configurations [14]. These include flaws in steam generator tubes [18-23], fatigue cracks [24-26], corrosion [27-33], material microstructure near welds [34], and estimation of pearlite percentages in plain carbon steels [35, 36] and in cast irons [37]. High density eddy current C-Scan data has also been used for the analysis of bolt hole eddy current [38] and estimation of micro-crack lengths [39]. For sub-millimetric applications, an array probe has been used for imaging of surfacebreaking defects in bore holes of metallic parts [40]. The effectiveness and reliability of ECT for the detection of surface-breaking cracks in cast stainless steel reactor components has also been studied [41].

ECT has been applied to measure probe-to-specimen spacing, known as lift-off. Applications like paint and metal deposition thickness measurement are well-known [42]. However, the potential for surface profiling is not as well recognized. In one case, eddy current probe output was combined with high density C-Scan data to extract information regarding local deformations and wear on the inner surfaces of pressure tubes [43]. This application produced topographic images of a specimen; however, the study did not calibrate lift-off response and therefore, did not quantify the size of features in the pipe. The extraction of surface damage measurements via ECT represents an attractive alternative to traditional depth gauge methods, since it can substantially reduce inspection time, store data for further analysis and retrieval, and makes use of technology and trained personnel that are already part of the aircraft maintenance program.

This study investigated the feasibility of using eddy current testing, combined with high density C-Scan information, as a method of evaluating surface damage due to denting on aluminum honeycomb sandwich aircraft panels. An ECT pencil probe was retrofitted to a servo controlled CScan apparatus and probe output was calibrated to lift-off $(\mathrm{mm})$. Measurements were compared to those taken on the same panel using an optical 3D scanning method [44], as well as with identifications made by inspection personnel as shown on the panel in Figure 1.

\section{Materials and Methods}

Surface damage was quantified on a retired honeycomb sandwich panel that had been used in a military helicopter. This panel had properties as listed in Table 1.

Table 1. Panel specifications

\begin{tabular}{cc}
\hline Property & Specification \\
\hline Top face sheet material & $\mathrm{Al} 7075-\mathrm{T} 6$ \\
Core material & $\mathrm{Al} 5052$ \\
Bottom face sheet material & Epoxy/fiberglass \\
Adhesive & ${\text { Heat-resistant epoxy Hysol }{ }^{\circledR} \text { EA } 934 \mathrm{NA}}^{\prime \prime}$ \\
Total panel thickness & $12.7 \mathrm{~mm}\left(0.50^{\prime \prime}\right)$ \\
Top face sheet thickness & $0.51 \mathrm{~mm}\left(0.020^{\prime \prime}\right)$ \\
Core thickness & $11.7 \mathrm{~mm}\left(0.46^{\prime \prime}\right)$ \\
Cell size & $3.2 \mathrm{~mm}\left(0.125^{\prime \prime}\right)$ \\
Cell wall thickness & $0.025 \mathrm{~mm}\left(0.001^{\prime \prime}\right)$ \\
\hline
\end{tabular}

A Nortec pencil probe, Z-145-P, which was attached via lever clamp to the C-Scan apparatus, was used to perform the ECT measurements. Prior to scanning, the panel was aligned with the scanning apparatus using alignment blocks placed at both ends of the panel to ensure equidistance 
from the scanning apparatus. Scanning was performed over a $205 \mathrm{~mm} \times 110 \mathrm{~mm}$ damage region (Figure 1), which contained approximately 14 dent impressions, with depths ranging from 0.13-1.01 $\mathrm{mm}$ as measured via optical 3D scanning. Optical 3D scanning was performed using a FARO ScanArm ${ }^{\circledR}$ measurement system mounted to a lab workstation with single point repeatability of 0.024 $0.064 \mathrm{~mm}$. Subsequent analysis of the 3D scan data was performed using Geomagic Design $\mathrm{X}^{\mathrm{TM}}$ software.

Eddy current signals were generated and received via an Olympus NDT MultiScan MS 5800 eddy current instrument. This instrument was used to perform input and output signal quadrature, displayed as Lissajous plots on an impedance plane as part of the data processing method, as well as handle the complex (real and imaginary) voltage input and output for the system. The operating frequencies for the probe were $25,100,400$ and $1,600 \mathrm{kHz}$.

TecView software was used to control the automated scanning apparatus. This included defining the $(X, Y)$ coordinate axes of the damage region for the $C$-scan, as well as specifying the path of the probe during the scanning process. Figure 1 shows the setup of the triple-axis scanning apparatus, with reference to the probe and aircraft panel. The sampling interval of the C-Scan was set to $1 \mathrm{~mm}$, which yielded 22,550 separate measurements. The raw output data was converted to liftoff (Z-axis) using height calibration curves developed prior to scanning.

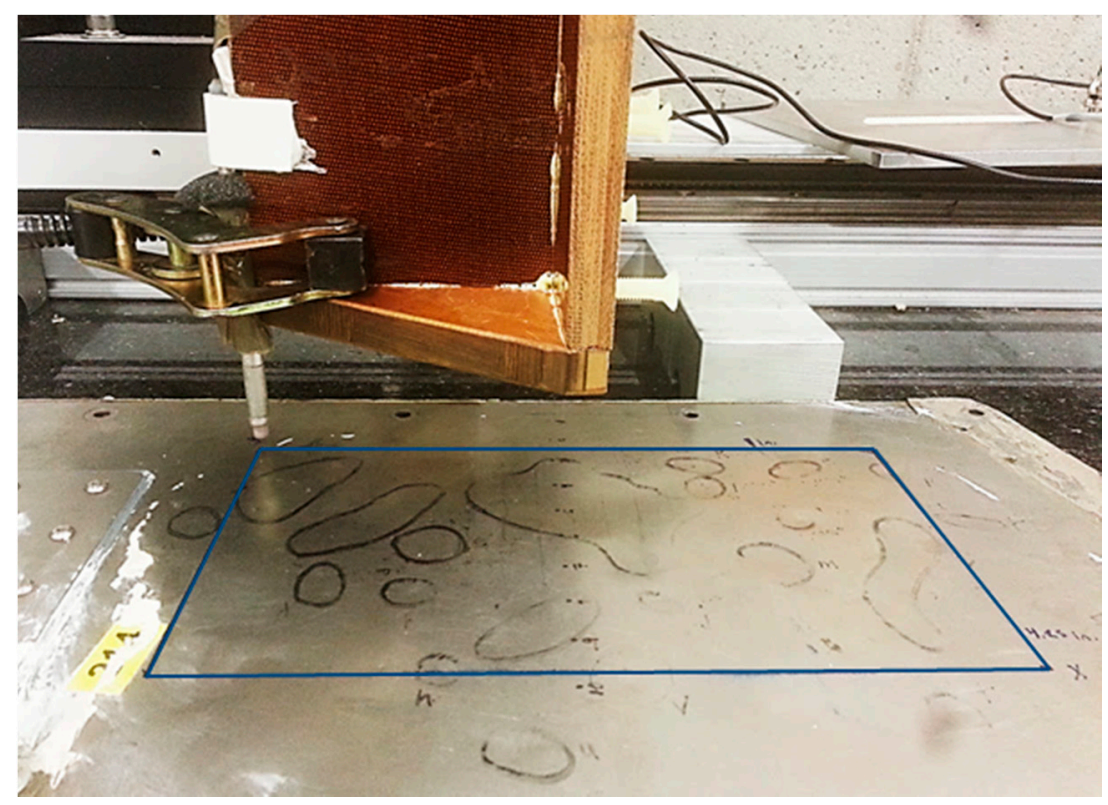

Figure 1. Experimental setup with outlined visual inspection results of sample.

The ECT acquisition software used in conjunction with the MS 5800 eddy current instrument was MultiView 6.1. Probe setting specification and control were performed within MultiView; namely, starting and stopping probe input, and presenting output data from the probe in real-time (strip chart display). Balancing of the probe was likewise conducted in MultiView with the probe located at an undented point on the panel surface. Nulling at this location meant that the change in signal observed when moving over a dent impression could be interpreted as lift-off. In addition, the output signal (or locus), response to lift-off, was aligned in MultiView display software such that the lift-off component of the signals was aligned with the Y-axis of the C-Scan output.

The operating frequencies and voltage of the probe were selected such that signal saturation was not observed and eddy currents would not penetrate deeper than the $0.5 \mathrm{~mm}$ thickness of the upper Al skin layer at the highest frequency of $1,600 \mathrm{kHz}$. For the given specimen, through-thickness penetration would skew and complicate the surface profiling results based on the complex interior of the honeycomb sandwich panel, which included adhesive and crushed aluminum honeycomb core. However, testing at lower frequencies, including $25 \mathrm{kHz}$, offered the added potential of inspecting the core geometry of the panel. Using relative permeability, $\mu_{r}=1$ and electrical 
conductivity, $\sigma=32 \% \mathrm{IACS}=1.89 \times 10^{7} \mathrm{~S} / \mathrm{m}$ for Al 7075-T6 [45], theoretical depths of penetration were calculated at the four testing frequencies using Equation 1 from [45] as tabulated in Table 2.

$$
\text { Depth of Penetration, } \delta=1 / \sqrt{ }(\pi \mathrm{f} \mu \sigma) \text {, }
$$

Table 2. Depth of penetration analysis.

\begin{tabular}{ccc}
\hline Frequency $[\mathrm{kHz}]$ & $\begin{array}{c}\text { Theoretical Depth of } \\
\text { Penetration, } \boldsymbol{\delta}[\mathrm{mm}]\end{array}$ & $\begin{array}{c}\text { \% Penetration } \mathbf{( 3 \delta} \text { ) into } \\
\text { Exposed Face Sheet } \\
\text { Thickness }\end{array}$ \\
\hline 25 & 0.73 & 429 \\
100 & 0.36 & 213 \\
400 & 0.18 & 105 \\
1,600 & 0.09 & 54 \\
\hline
\end{tabular}

A calibration test was performed prior to the C-Scan process, which produced curves for converting the probe output data to lift-off $(\mathrm{mm})$ at the four frequencies, simultaneously. Note that only the $1,600 \mathrm{kHz}$ signal gave a penetration, $3 \delta$ that was less than the face sheet thickness $(3 \delta=0.27$ $\mathrm{mm}$, which was smaller than the $0.5 \mathrm{~mm}$ face sheet thickness). The lower frequency results with $3 \delta$ being larger than the thickness of the face sheet may be invalid due to sensing of face sheet thickness variations or honeycomb structure beneath the face sheet. This test was performed in the same location as the probe balance point within the damage region. Data was extracted at a $0.1 \mathrm{~mm}$ resolution over a lift-off range of $3.2 \mathrm{~mm}$ (Z-axis) starting from contact. This produced 33 data points, as shown in Figure 2, which were linearly interpolated to produce the calibration curves.

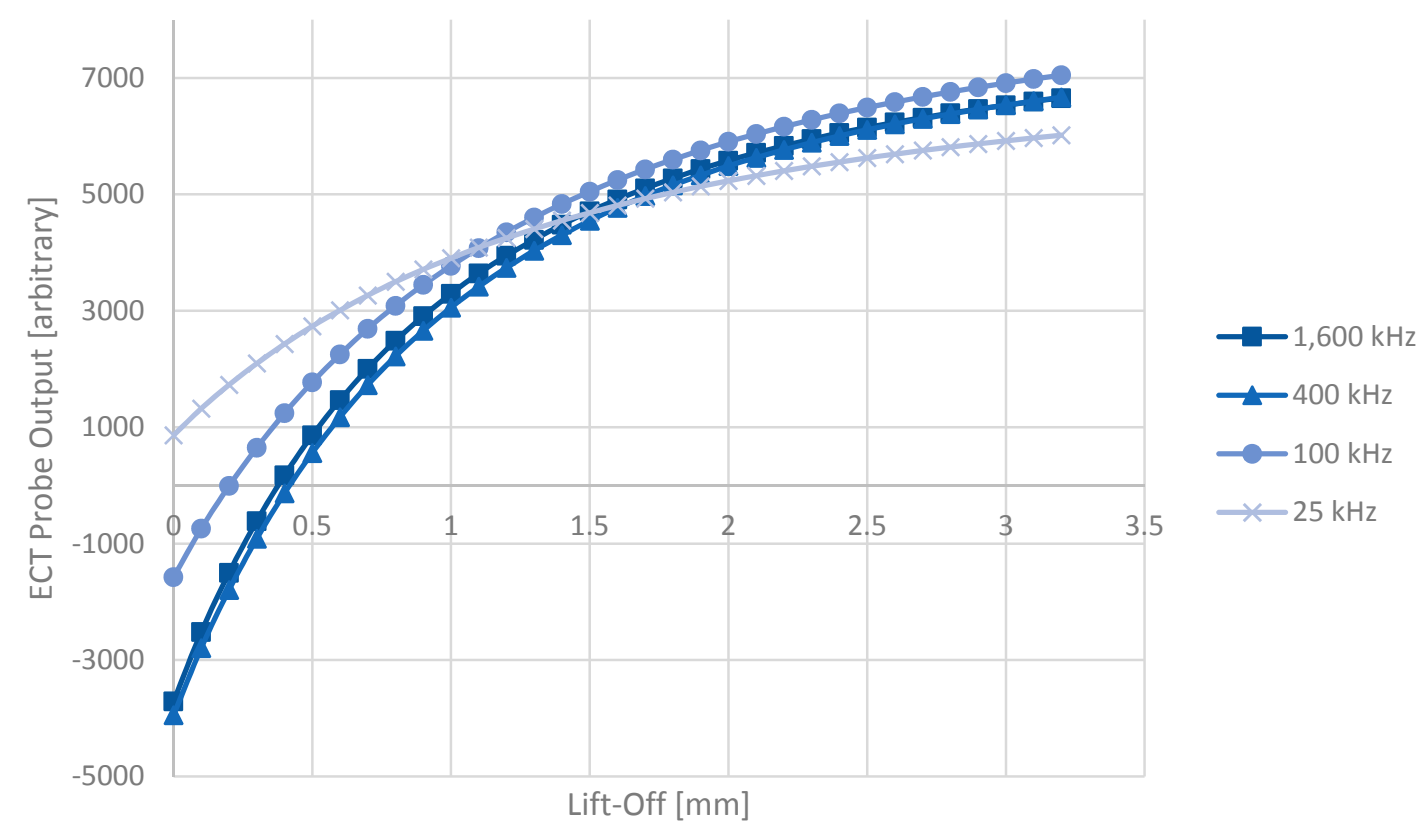

Figure 2. ECT calibration curves at various frequencies; probe output vs. lift-off [mm].

It was necessary to define a new reference surface for the eddy current lift-off measurements at each frequency, which approximated the original, undamaged surface of the panel. This is because the 2D C-Scan plane did not exactly match the plane of the aircraft panel, which demonstrated some curvature. The new reference surface for each frequency was thus three-dimensional in nature, defined using Equation 2, where $Z(x, y)$ and $Z^{\prime}(x, y)$ represent the original and adjusted eddy current measurements, respectively. The values of $A, B, C$ and $D$ were chosen to minimize the residual sum 
square (RSS) difference between the reference surface and the adjusted eddy current measurements at the edges of the damage region.

$$
Z^{\prime}(x, y)=(Z(x, y)-(A X+B Y+C X Y+D)),
$$

To validate the eddy current results, an $11 \times 21$ grid of measurement points with $10 \mathrm{~mm}$ spacing was exported from the optical 3D scanning software to compare with the corresponding eddy current measurements made within the damage region. This grid of comparison points was specified as shown in Figure 3 within the 3D scanning software.

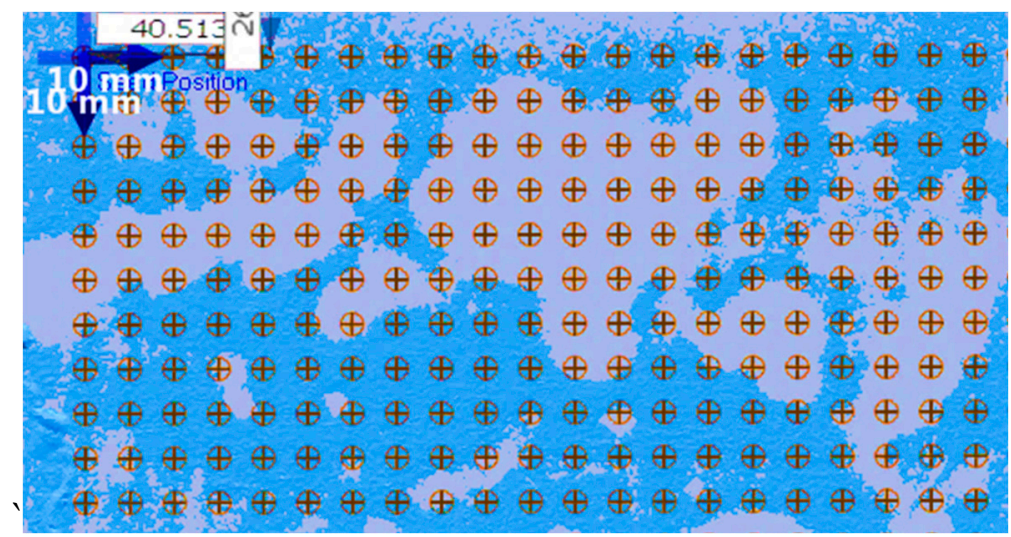

Figure 3. $11 \times 21$ grid of comparison points for damage region as evaluated within 3D scanning software; blue patterned background is 3D scan point cloud data.

\section{Results}

The process of defining a reference surface for the eddy current measurements yielded coefficient values for Equation 2 as shown in Table 3 for each frequency.

Table 3. Equation 2 coefficient values.

\begin{tabular}{cccccc}
\hline \multirow{2}{*}{ Frequency [kHz] } & \multicolumn{4}{c}{ Coefficient, Equation 2 } & \multirow{2}{*}{ Resultant RSS Difference } \\
\cline { 2 - 5 } & A & B & C & D & 0.0029 \\
25 & -0.18 & 0.38 & 0.0011 & -0.19 & 0.0065 \\
100 & -0.23 & 0.069 & 0.0014 & 0.16 & 0.056 \\
400 & -0.24 & -0.13 & 0.0015 & 0.30 & 0.042 \\
1,600 & -0.22 & -0.10 & 0.0013 & 0.28 & \\
\hline
\end{tabular}

Figure 4 shows a visual comparison of the surface contour plots developed for the eddy current measurements at each frequency. 


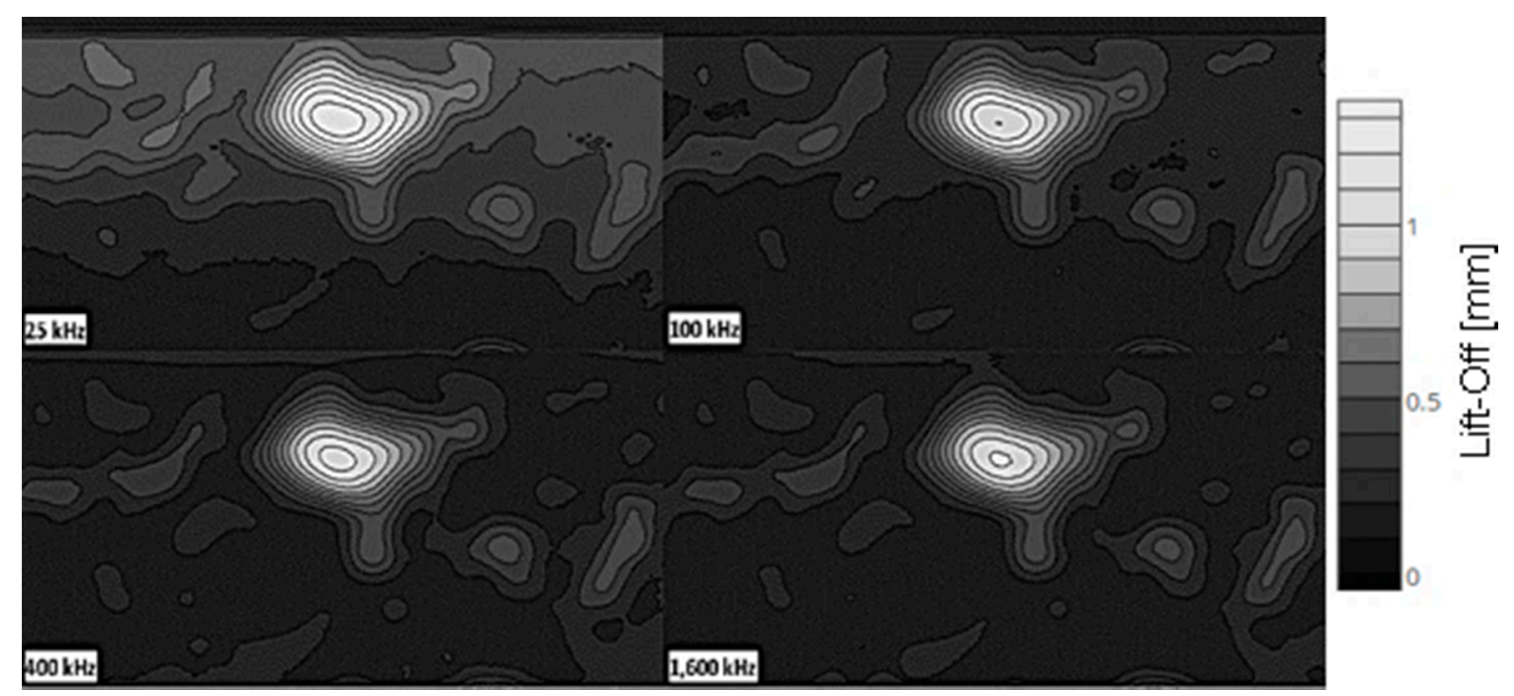

Figure 4. Four frequency comparison.

Figure 5 shows a comparison between a photograph of the damaged panel surface with demarcated dent regions, the 3D scanning results, and a contour map of the $1,600 \mathrm{kHz}$ eddy current measurements. Note the comparatively higher resolution obtained from the $1 \mathrm{~mm} \times 1 \mathrm{~mm}$ sampling grid of the ECT C-Scan.

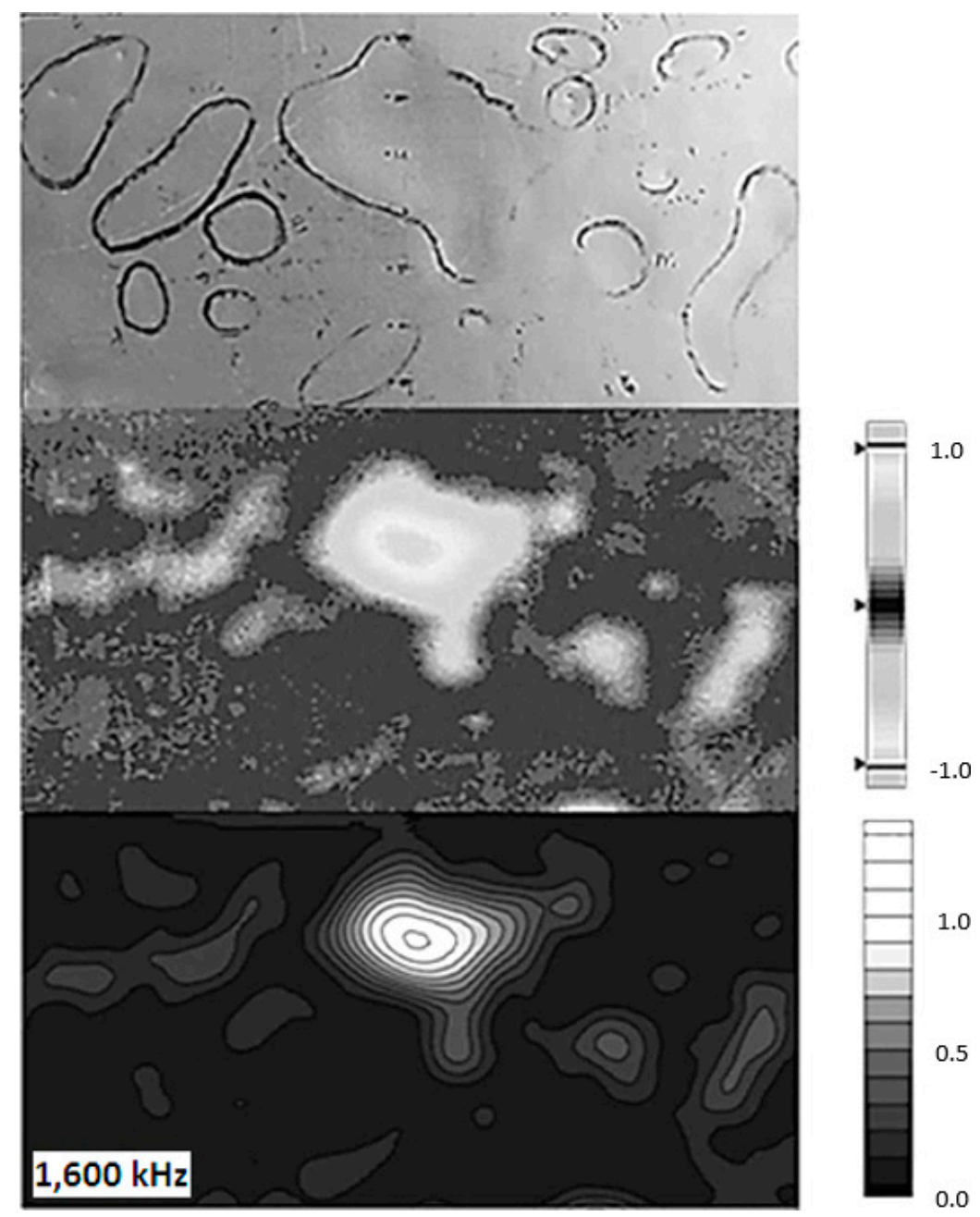

Figure 5. Damage region (top); 3D scanning deviation map (middle); 1,600 kHz ECT contour map (bottom). 
Error was evaluated to two standard deviations between the eddy current results, at each frequency, and optical 3D scanning measurements at 231 points, as tabulated in Table 4. Maximum absolute difference reported the maximum difference calculated between the ECT and 3D scanning results. A depth (ECT) versus depth (3D scanning) plot was developed as shown in Figure 6 for the $1,600 \mathrm{kHz}$ data, where the line represents the ideal case of the ECT results being equal to the $3 \mathrm{D}$ scanning results.

Table 4. Error analysis.

\begin{tabular}{ccc}
\hline Frequency $[\mathrm{kHz}]$ & $\begin{array}{c}\text { Error (Two Standard } \\
\text { Deviations) }[\mathrm{mm}]\end{array}$ & $\begin{array}{c}\text { Maximum Absolute } \\
\text { Difference }[\mathrm{mm}]\end{array}$ \\
\hline 25 & 0.240 & 0.40 \\
100 & 0.069 & 0.16 \\
400 & 0.056 & 0.15 \\
1,600 & 0.052 & 0.14 \\
\hline
\end{tabular}

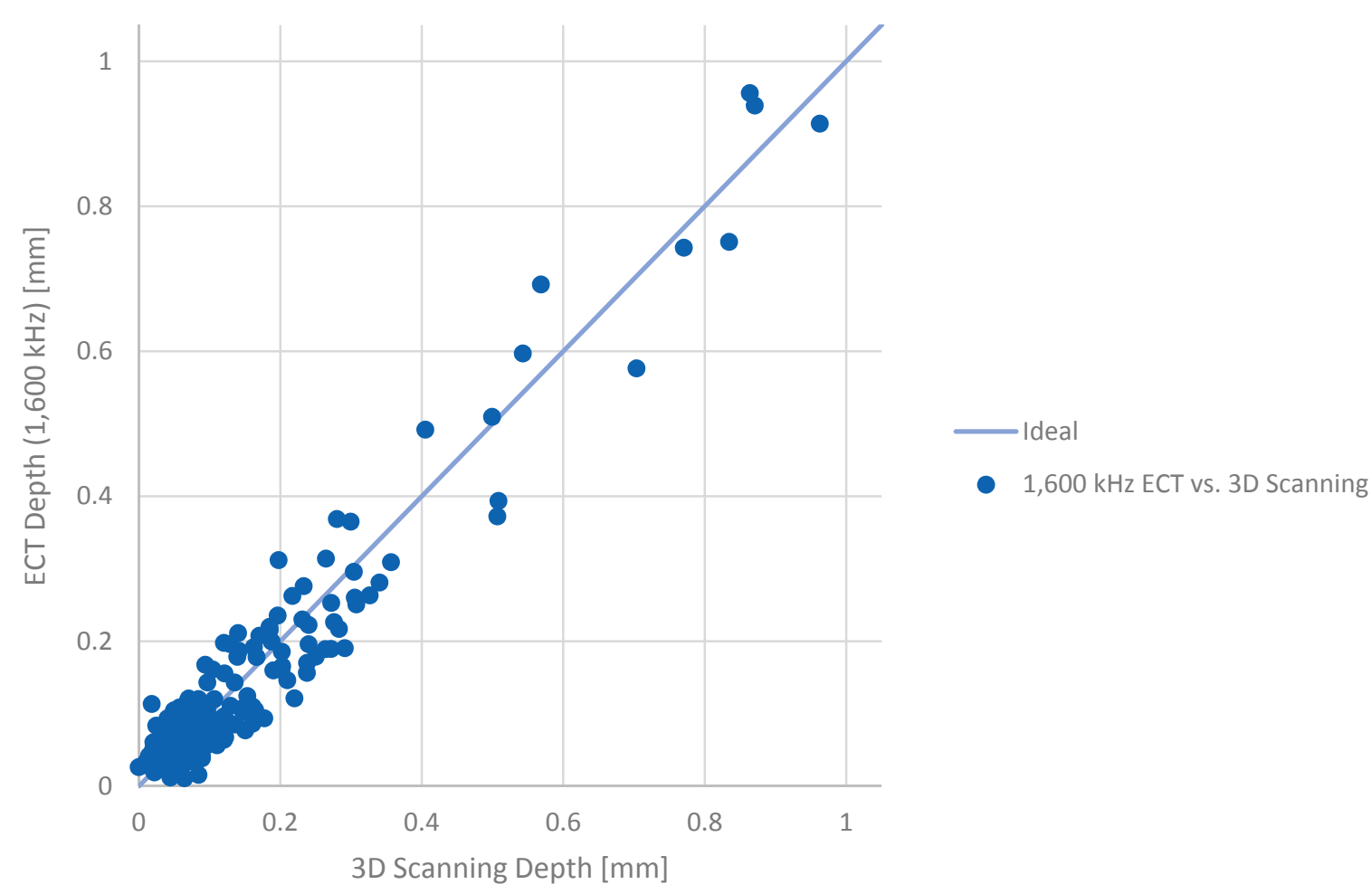

Figure 6. Dent Depth (ECT) vs. Dent Depth (3D Scanning Method).

\section{Discussion}

Of the four frequencies, the $1,600 \mathrm{kHz}$ results were the most accurate in terms of surface profiling capability, matching the maximum dent depth $(1.01 \mathrm{~mm})$ identified within the damage region, while also yielding the lowest error to two standard deviations $(0.05 \mathrm{~mm})$ and maximum absolute difference $(0.14 \mathrm{~mm})$ compared with the 231 optical 3D scanning measurements.

The ECT results also demonstrated potential for improved capability for dent characterization compared with visual methods. This was seen within the portion of the damage region shown in Figure 7, where the contour map of the eddy current measurement results varied from the identifications made by visual inspection personnel. This is valuable for accurately measuring dent lengths and areas, which are target parameters of aircraft panel surface inspections. These parameters may also be evaluated using the described ECT method by performing image processing of the contour maps obtained from the ECT measurement results. 


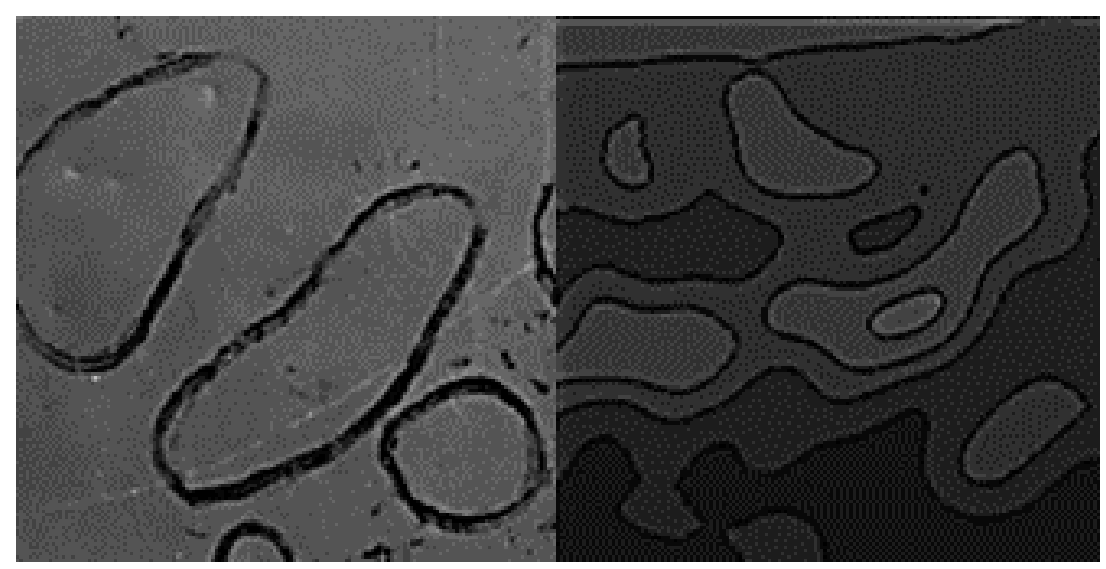

Figure 7. Dent identification comparison; inspection personnel (left) vs. ECT method (right).

Compared with other surface damage inspection methods like optical 3D scanning, multifrequency eddy current testing offers the additional benefit of internal inspection capability for aluminum honeycomb sandwich panels. This includes identification of variable thickness regions and evaluation of honeycomb core geometries. For instance, the eddy current measurements compiled at 25 and $100 \mathrm{kHz}$ revealed a second layer of aluminum beneath the top face sheet at the top of the damage region. This was confirmed by cutting the panel, which revealed the second layer as shown in Figure 8.

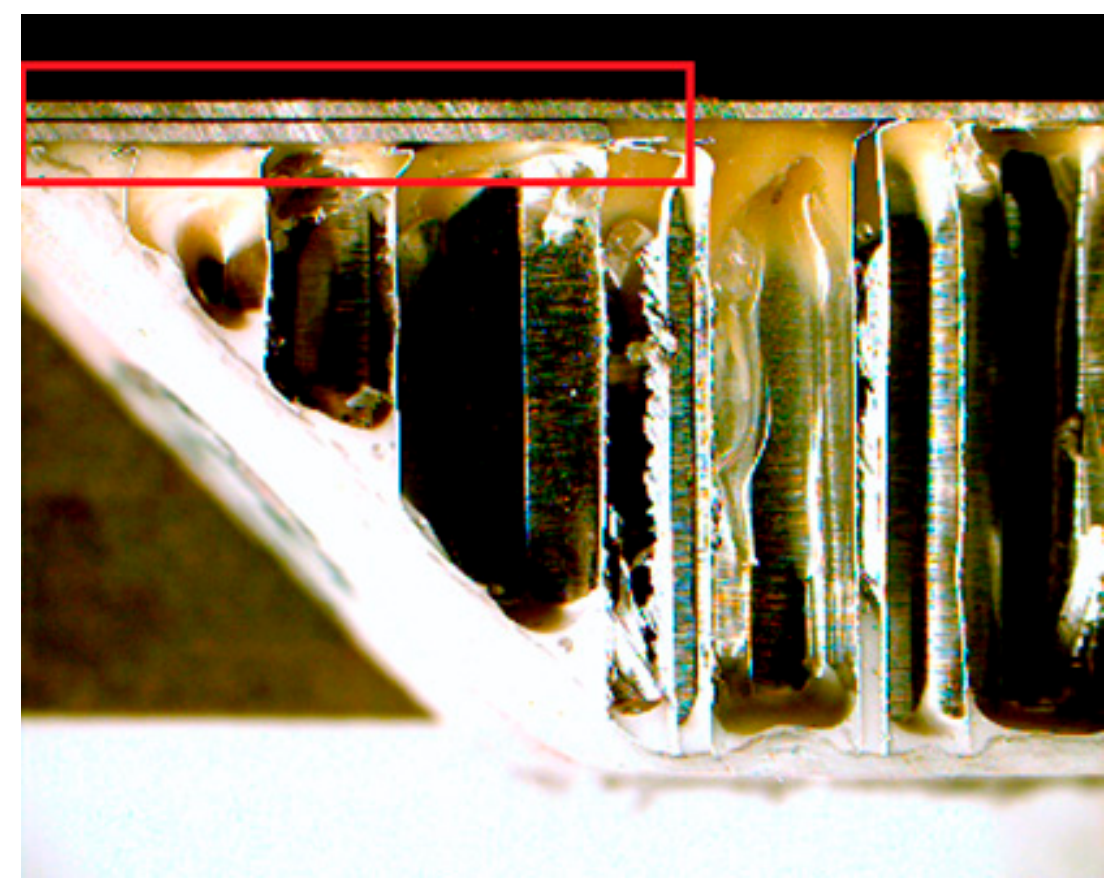

Figure 8. Second layer of aluminum identified under top face sheet near top of damage region close to panel flange.

Plotting the low $25 \mathrm{kHz}$ frequency results in Excel likewise allowed characterization of the hexagonal cell geometries located beneath the top face sheet, shown in Figure 9. Measurement of the contours confirmed the honeycomb core cell size as $3.2 \mathrm{~mm}$, which agreed with destructive examination as shown in Figure 10. Linear contour plotting of the $25 \mathrm{kHz}$ results in graphing software, Plotly, also enabled investigation of the core as shown in Figure 11 at a step size of 0.0015 $\mathrm{mm}$ compared to the same region observed visually. 


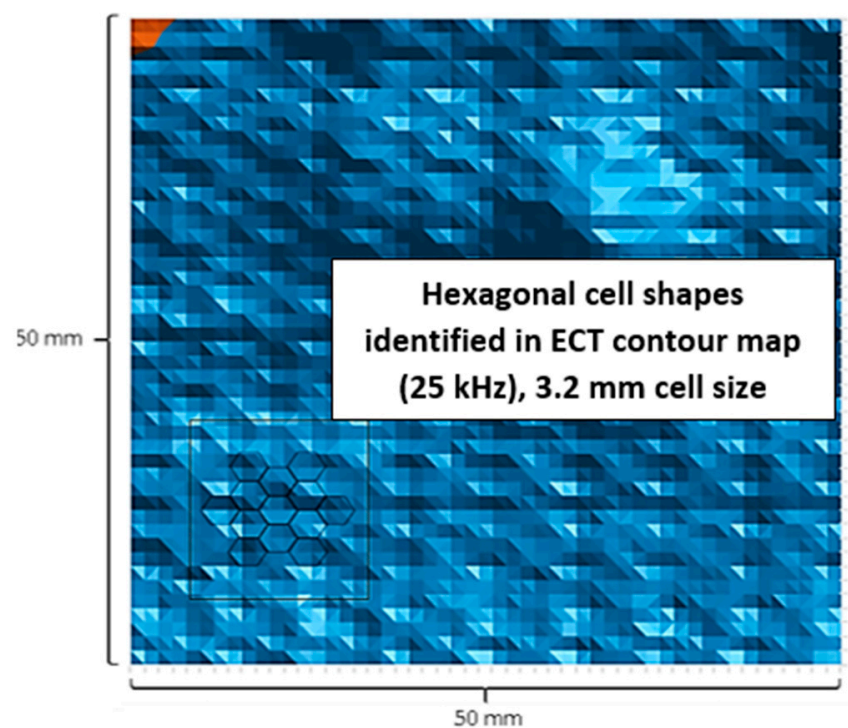

Figure 9. ECT core evaluation with identified cell geometries (Excel) [25 kHz].

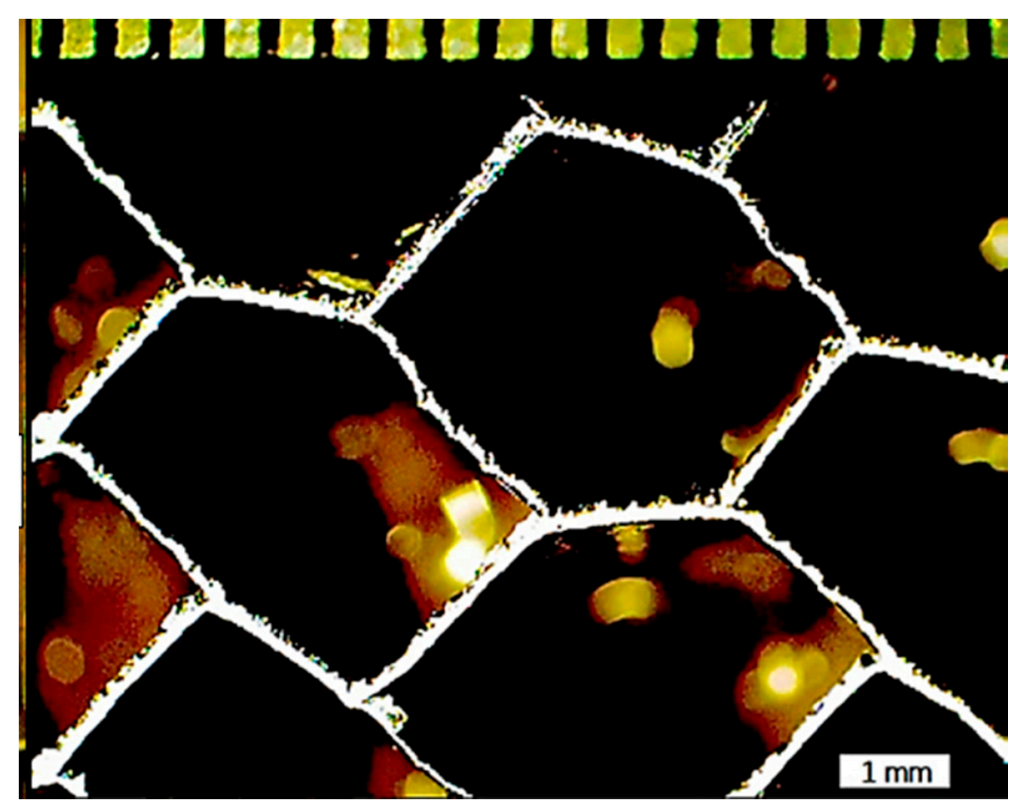

Figure 10. Honeycomb core cell geometry obtained from destructive examination. Demarcations at top of Figure are half mm intervals. 


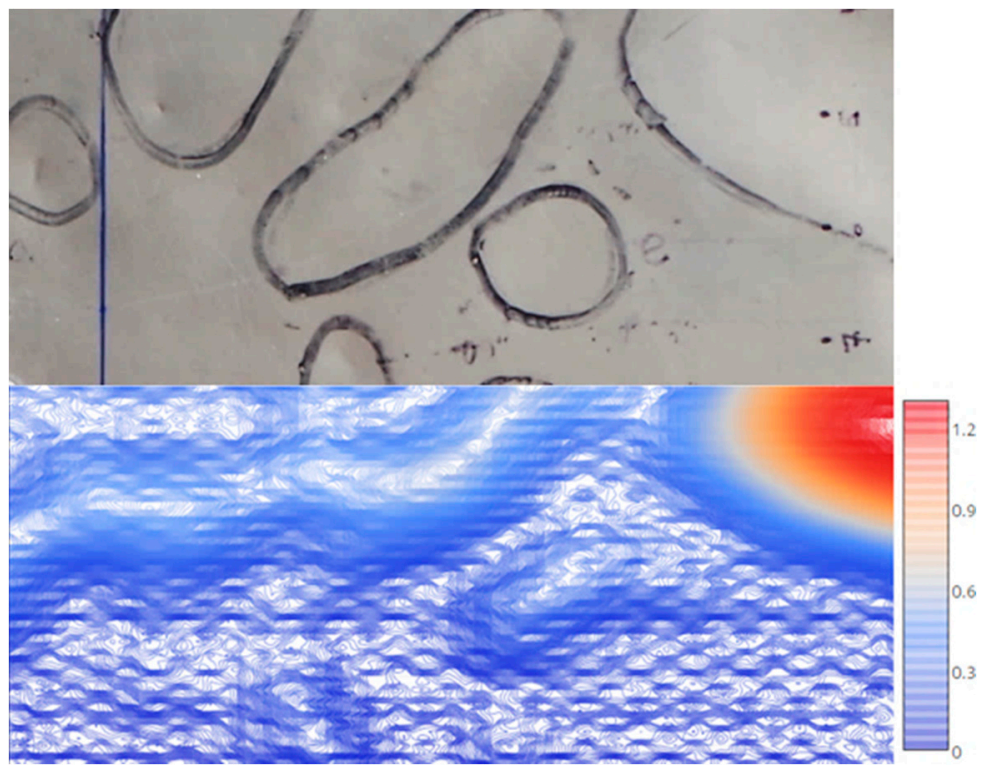

Figure 11. ECT core evaluation; panel surface (top) and ECT results plotted in Plotly, $0.0015 \mathrm{~mm}$ contour step size (bottom) [25 kHz].

There is potential for in-field implementation of this method using portable eddy current technologies. These would likely involve scanning of aircraft surfaces with a handheld eddy current array system combined with encoder information. For the evaluation of entire panel surfaces, it is assumed that the described ECT method would decrease inspection time due to automated extraction and compilation of damage geometry information, and would enhance reliability of the measurements. Greater measurement density may also be achieved using ECT compared to the 3D scanning method, where it was observed that the output capability of the ECT method $(22,550$ measurements) was two magnitudes higher than that achievable using the 3D scanning software, but this may be a limitation of the particular 3D scanning software that was implemented.

\section{Conclusions}

ECT was investigated as a method of surface profiling for an all-aluminum honeycomb sandwich aircraft panel. Comparison of the method at $1,600 \mathrm{kHz}$ with 231 optical 3D scanning measurements demonstrated that the eddy current results were accurate to within $0.052 \mathrm{~mm}$ (two standard deviations). Lower frequency testing at $25 \mathrm{kHz}$ also proved feasible for the evaluation of internal core geometries. ECT-based methods hold the potential for rapid and reliable means of measuring dent depths, lengths and areas. As a result, this novel technique has the potential to provide timely extraction of surface damage measurements for on-site component examination.

Acknowledgments: Aerospace Research Advisory Committee (AERAC), Director Technical Airworthiness and Engineering Support (DTAES).

Author Contributions: T. Reyno, P.R. Underhill, T.W. Krause, C. Marsden and D. Wowk conceived and designed the experiments; T. Reyno and P.R. Underhill performed the experiments; T. Reyno and P.R. Underhill analyzed the data; T. W. Krause, C. Marsden and D. Wowk contributed reagents, materials and analysis tools; T. Reyno, P.R. Underhill and T. W. Krause wrote the paper.

Conflicts of Interest: The authors declare no conflict of interest. The founding sponsors had no role in the design of the study; in the collection, analyses, or interpretation of data; in the writing of the manuscript, and in the decision to publish the results.

\section{References}

1. Hsu, D.K. Nondestructive Evaluation of Sandwich Structures: A Review of Some Inspection Techniques. Journal of Sandwich Structures \& Materials 2009, 11, 276-291, 10.1177/1099636209105377. 
2. Eisenberg, D. Evaluation of Quasi-Static Indentation Damage in Aluminum Honeycomb Core Graphite/Epoxy Sandwich Structures. Honors Program Capstone Project, Syracuse University, Syracuse, New York, 2010.

3. Kalms, M; Jueptner, W. A Mobile Shearography System for Non-Destructive Testing of Industrial and Artwork Components. KEY ENG MAT 2005, 295-296, 165-170, 10.4028/www.scientific.net/KEM.295296.165.

4. Shipsha, A.; Zenkert, D. Compression-after-Impact Strength of Sandwich Panels with Core Crushing Damage. Applied Composite Materials 2005, 12, 149-164, https://doi.org/10.1007/s10443-005-1119-1.

5. Edgren, F.; Asp, L.E.; Bull, P.H. Compressive Failure of Impacted NCF Composite Sandwich Panels Characterisation of the Failure Process. Journal of Composite Materials 2004, 38, 495-514, 10.1177/0021998304040559.

6. Zenkert, D.; Shipsha, A.; Bull, P.; Hayman, B. Damage tolerance assessment of composite sandwich panels with localised damage. Composites Science and Technology 2005, 65, 2597-2611, 10.1016/j.compscitech.2005.05.026.

7. Shi, M.; Brindza, J.; Michel, P.; Bucklin, P. et al. Static and Dynamic Dent Resistance Performance of Automotive Steel Body Panels. SAE Technical Paper Series 1997, 10.4271/970158.

8. Ekstrand, G.; Asnafi, N. On testing of the stiffness and the dent resistance of autobody panels. Materials $\mathcal{E}$ Design 1998, 19, 145-156, 10.1016/s0261-3069(98)00028-4.

9. Asnafi, N. On strength, stiffness and dent resistance of car body panels. Journal of Materials Processing Technology 1995, 49, 13-31, 10.1016/0924-0136(94)01333-v.

10. Asnafi, N.; Langstedt, G.; Andersson, C.; Östergren, N; Håkansson, T. A new lightweight metal-compositemetal panel for applications in the automotive and other industries. Thin-Walled Structures 2000, 36, 289310, 10.1016/s0263-8231(00)00004-5.

11. Laliberté, J.; Straznicky, P.; Poon, C. Impact Damage in Fiber Metal Laminates, Part 1: Experiment. AIAA Journal 2005 43, 2445-2453, 10.2514/1.15159.

12. Raju, K.; Smith, B.; Tomblin, J.; Liew, K.; Guarddon, J. Impact Damage Resistance and Tolerance of Honeycomb Core Sandwich Panels. Journal of Composite Materials 2008, 42, 385-412, 10.1177/0021998307088596.

13. Růžek, R.; Lohonka, R.; Jironč, J. Ultrasonic C-Scan and shearography NDI techniques evaluation of impact defects identification. NDT E E International 2006, 39, 132-142, 10.1016/j.ndteint.2005.07.012.

14. Ghoni, R.; Dollah, M.; Sulaiman, A.; Ibrahim, F. Defect Characterization Based on Eddy Current Technique: Technical Review. Advances in Mechanical Engineering 2014, 6, 182496, 10.1155/2014/182496

15. Diaz, A.A.; Mathews, R.A. Assessment of eddy current testing for the detection of cracks in cast stainless steel reactor piping components. Pacific Northwest National Laboratory 2007. Available online: https://www.nrc.gov/reading-rm/doc-collections/nuregs/contract/cr6929/\#pub-info

16. Grman, J.; Syrova, L. Classifiability analysis of indications by eddy-current testing of nuclear power plant heat-exchanger tube. In Radioelektronika, 2009. RADIOELEKTRONIKA '09. 19th International Conference, Bratislava, Slovakia, Apr. 22-23, 2009, 287-90, 10.1109/RADIOELEK.2009.5158772.

17. Tian, S.; Chen, Z.; Ueda, M.; Yamashita, T. Signal processing schemes for Eddy Current Testing of steam generator tubes of nuclear power plants. Nuclear Engineering and Design 2012, 245, 78-88, 10.1016/j.nucengdes.2011.12.033.

18. Siegel, J. Detecting SG tube cracks in difficult places. Nuclear Engineering International 1996, 41, 18-19, 10.1016/0140-6701(96)87590-4.

19. Hur, D.; Choi, M.; Lee, D.; Kim, S.; Han, J. A case study on detection and sizing of defects in steam generator tubes using eddy current testing. Nuclear Engineering and Design 2010, 240, 204-208, 10.1016/j.nucengdes.2009.10.006.

20. Xin, J.; Lei, N.; Udpa, L.; Udpa, S. Rotating field eddy current probe with bobbin pickup coil for steam generator tubes inspection. NDT \& E International 2013, 54, 45-55, 10.1016/j.ndteint.2012.12.002.

21. Li, Y.; Udpa, L.; Udpa, S. Three-Dimensional Defect Reconstruction From Eddy-Current NDE Signals Using a Genetic Local Search Algorithm. IEEE Transactions on Magnetics 2004, 40, 410-417, 10.1109/tmag.2004.824116.

22. Kim, Y.; Lee, S. Eddy current probes of inclined coils for increased detectability of circumferential cracks in tubing. NDT E E International 2012, 49, 77-82, 10.1016/j.ndteint.2012.04.004. 
23. Todorov, E. Measurement of electromagnetic properties of heat exchanger tubes with model-based eddy current technique. NDT E E International 2012, 48, 70-76, 10.1016/j.ndteint.2012.02.006.

24. Underhill, P.R.; Krause, T.W. Eddy current analysis of mid-bore and corner cracks in bolt holes. NDT E E International 2011, 44, 513-518, 10.1016/j.ndteint.2011.05.007.

25. Abidin, I.; Mandache, C.; Tian, G.; Morozov, M. Pulsed eddy current testing with variable duty cycle on rivet joints. NDT \& E International 2009, 42, 599-605, 10.1016/j.ndteint.2009.04.001.

26. Babbar, V.; Underhill, P.; Stott, C.; Krause, T. Finite element modeling of second layer crack detection in aircraft bolt holes with ferrous fasteners present. NDT $\mathcal{E}$ E International 2014, 65, 64-71, 2014, 10.1016/j.ndteint.2014.03.005.

27. Yusa, N.; Perrin, S.; Mizuno, K.; Miya, K. Numerical modeling of general cracks from the viewpoint of eddy current simulations. NDT E E International 2007, 40, 577-583, 10.1016/j.ndteint.2007.04.002.

28. Yusa, N.; Chen, Z.; Miya, K. Sizing of stress corrosion cracking on austenitic stainless piping in a nuclear power plant from eddy current NDT signals. Nondestructive Testing and Evaluation 2005, 20, 103-114, 10.1080/10589750500209554.

29. Yusa, N.; Chen, Z.; Miya, K.; Uchimoto, T.; Takagi, T. Large-scale parallel computation for the reconstruction of natural stress corrosion cracks from eddy current testing signals. NDT $\mathcal{E}$ E International 2003, 36, 449-459, 10.1016/s0963-8695(03)00067-7.

30. Miya, K.; Aoto, K.; Chen, Z. Reconstruction of cracks with physical closure from signals of eddy current testing. IEEE Transactions on Magnetics 2000, 36, 1018-1022, 10.1109/20.877614.

31. Yusa, N.; Huang, H.; Miya, K. Numerical evaluation of the ill-posedness of eddy current problems to size real cracks. NDT \& E International 2007, 40, 185-191, 10.1016/j.ndteint.2006.10.012.

32. Yusa, N.; Miya, K. Discussion on the equivalent conductivity and resistance of stress corrosion cracks in eddy current simulations. NDT \& E International 2009, 42, 9-15, 10.1016/j.ndteint.2008.09.007.

33. Ramos, H.; Rocha, T.; Král, J.; Pasadas, D.; Ribeiro, A. An SVM approach with electromagnetic methods to assess metal plate thickness. Measurement 2014, 54, 201-206, 10.1016/j.measurement.2014.01.035.

34. Zergoug, M.; Lebaili, S.; Boudjellal, H.; Benchaala, A. Relation between mechanical microhardness and impedance variations in eddy current testing. NDT $\mathcal{E} E$ International 2004, 37, 65-72, 10.1016/j.ndteint.2003.09.002.

35. Khan, S.; Ali, F.; Khan, A.; Iqbal, M. Pearlite determination in plain carbon steel by eddy current method. Journal of Materials Processing Technology 2008, 200, 316-318, 10.1016/j.jmatprotec.2007.09.003.

36. S. Konoplyuk, "Estimation of pearlite fraction in ductile cast irons by eddy current method," NDT and E International, vol. 43, no. 4, pp. 360-364, 2010.

37. Ghanei, S.; Kashefi, M.; Mazinani, M. Eddy current nondestructive evaluation of dual phase steel. Materials $\mathcal{E}$ Design 2013, 50, 491-496, 10.1016/j.matdes.2013.03.040.

38. Underhill, P.R.; Krause, T.W. Enhancing Probability of Detection and Analysis of Bolt Hole Eddy Current. Journal of Nondestructive Evaluation 2011, 30, 237-245, 10.1007/s10921-011-0112-x.

39. Bodruzzaman, M.; Zein-Sabatto, S. Estimation of micro-crack lengths using eddy-current c-scan and neural-wavelet transform. In Southeastcon, 2008. IEEE. Huntsville, AL, USA, Apr. 3-8, 2008, 551-556, 10.1109/SECON.2008.4494355.

40. Joubert, P.; Vourc'h, E.; Thomas, V. Experimental validation of an eddy current probe dedicated to the multi-frequency imaging of bore holes. Sensors and Actuators A: Physical 2012, 185, 132-138, 10.1016/j.sna.2012.07.009.

41. Beamand, J. H. Multiprobe Multiplexed Eddy Current System for the Detection of Stress Corrosion Cracking in Stainless Steel Tube. In Non-Destructive Testing, Proceedings of the 4th European Conference, London, UK, Sep. 13- 17, 1987, 2632-636, 10.1016/B978-0-08-036221-2.50055-3.

42. ASM Handbook Volume 17: Nondestructive Evaluation and Quality Control; ASM International: ASM World Headquarters - Materials Park, Novelty, OH, USA, 1989; 154-196; 978-0-87170-023-0.

43. Shokralla, S.; Krause, T.; Morelli, J. Surface profiling with high density eddy current non-destructive examination data. NDT \& E International 2014, 62, 153-159, 10.1016/j.ndteint.2013.12.008.

44. Reyno, T. et al. Surface Damage Evaluation of Honeycomb Sandwich Aircraft Panels using 3D Scanning Technology.

45. Cecco, V.; Van Drunen, G.; Sharp, F. Eddy Current Manual Volume 1: Test Method; Chalk River, Ont.: Chalk River Nuclear Laboratories, Deep River, Renfrew County, Ontario, Canada, 1981. 